\title{
Fine-scale analysis of arrowtooth flounder Atherestes stomias catch rates reveals spatial trends in abundance
}

\author{
Stephani Zador ${ }^{1, *}$, Kerim Aydin ${ }^{1}$, Jason Cope ${ }^{2}$ \\ ${ }^{1}$ Resource Ecology and Fisheries Management Division, Alaska Fisheries Science Center, 7600 Sand Point Way NE, Seattle, \\ Washington 98115, USA \\ ${ }^{2}$ Fisheries Resource and Analysis Division, Northwest Fisheries Science Center, 2725 Montlake Blvd. E, Seattle, \\ Washington 98112, USA
}

\begin{abstract}
Multiple lines of evidence suggest that changes in the marine climate in the eastern Bering Sea are leading to numerical and distributional shifts in fish populations that may affect the balance of predator-prey relationships. A rapidly increasing arrowtooth flounder Atheresthes stomias population has prompted concern about the growing threat of arrowtooth flounder predation on economically valuable walleye pollock Theragra chalcogramma. The goal of this study was to investigate the overall increasing trend of arrowtooth flounder at a finer spatial resolution to better understand the potential spatial variability in their predatory impact under a changing climate. The specific objectives were to determine whether arrowtooth flounder were increasing equally throughout the eastern Bering Sea and, if not, (1) identify areas with dissimilar abundance trends and (2) explore physical and biological habitat characteristics that may be contributing to these differences. Clustering arrowtooth survey catch per unit effort revealed 4 distinct spatial groups showing stable, increasing, and variable trends. Increasing bottom water temperature and depth were associated with higher proportions of trawls containing arrowtooth and higher catch rates. Age- 1 and -2 pollock were the predominant prey in all areas, but higher rates of non-empty stomachs in the northwest region indicated that current predatory impacts on pollock may be higher there. Favorable physical habitat (deep and warm) and diet trends (full stomachs) suggest that arrowtooth flounder in the northwest region of the eastern Bering Sea have the potential to increase further, perhaps to the abundance levels seen in the high-density area where they may have reached carrying capacity.
\end{abstract}

KEY WORDS: Arrowtooth flounder - Atheresthes stomias - Bering Sea - Fish distribution . Cluster analysis $\cdot$ Predation $\cdot$ Walleye pollock $\cdot$ Climate change

\section{INTRODUCTION}

While the impacts of global climate change remain largely uncertain, several lines of evidence indicate that changes in marine climate beyond annual variability may be affecting the distribution of marine organisms in the eastern Bering Sea (EBS; Litzow \& Ciannelli 2007, Mueter \& Litzow 2008). Understanding variability in spatial distributions in marine organisms is an integral part of understanding how their populations change over time (Ciannelli et al. 2008). As species exhibit varying sensitivity to climatic influences, the resulting differences in the distribution and abundance of predators and prey may also influence the balance of predator-prey relationships. Furthermore, interactions between fish and the marine environment can differ at varying temporal and spatial scales (White \& Caselle 2008). As a 
consequence, different observational scales are likely to highlight different aspects of interactions between fish predators, their prey, and the marine environment (see review by Ciannelli et al. 2008). Moreover, ignoring spatial variation when summarizing observations may misrepresent underlying mechanisms (Thrush et al. 1994).

The EBS (Fig. 1) is characterized by a broad $(500 \mathrm{~km})$ and shallow $(<200 \mathrm{~m})$ continental shelf that is about $1200 \mathrm{~km}$ from north to south. The shelf is strongly influenced by seasonal sea ice, which is an important regulator of the timing of the spring phytoplankton bloom and of the extent of the cold pool of bottom water that persists on the shelf during summer (Stabeno \& Hunt 2002, Wyllie-Echeverria \& Wooster 2002, Stabeno et al. 2007). High biological productivity supports diverse and abundant pelagic and benthic communities. At least 40 species of fish, crabs, and squid are commercially harvested to some degree with trawl, longline, or pot gear (NPFMC 2010b). Walleye pollock Theragra chalcogramma (hereafter 'pollock') have dominated the biomass of groundfish in the EBS since the 1980s, although they recently exhibited a 5 yr decline (Ianelli et al. 2010). They are the basis of the largest US single-species fishery, valued at US\$366.1 million in 2007 for the fish alone, the majority of which are caught with trawl gear (Hiatt et al. 2009).

Arrowtooth flounder Atheresthes stomias (hereafter 'arrowtooth') are piscivorous flatfish that have little commercial value and are difficult to target for a fishery because of the bycatch of Pacific halibut Hippoglossus stenolepis which commonly occupy the same habitat. Pacific halibut are a prohibited species that cannot be retained in groundfish fisheries and

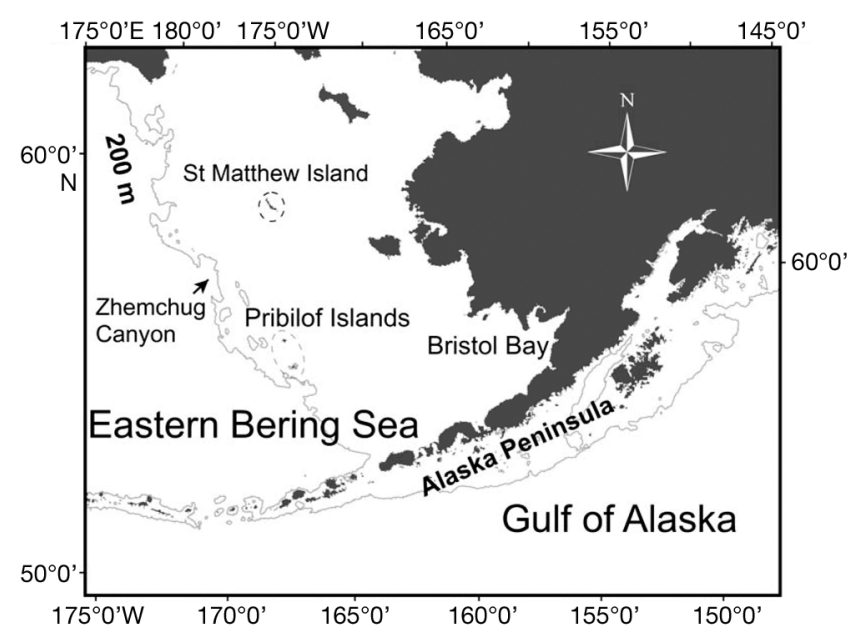

Fig. 1. Study area in the eastern Bering Sea, Alaska, USA must be discarded with a minimum of injury (Witherall \& Pautzke 1997). In the Gulf of Alaska (GoA), arrowtooth abundance has increased rapidly over the past 40 yr to become the most abundant groundfish (Turnock \& Wilderbuer 2009). In the EBS, arrowtooth have quadrupled since the mid-1970s and are currently the fifth most abundant groundfish species (Fig. 2; Wilderbuer et al. 2009). There is great interest in the ecological and economic impacts of the increasing arrowtooth population. There are concerns about the growing threat of arrowtooth predation on commercially valuable pollock, as well as a potential decrease in predation on juvenile arrowtooth by adult pollock, which may be important for regulating the growing predator population (Walters $\&$ Kitchell 2001). Given that the extent of spatial overlap of arrowtooth and pollock varies due to changes in their summer distribution across the EBS, it is important to know whether the increase in the arrowtooth population has been spatially heterogeneous to better understand changes in their potential predatory impact under a changing climate.

The goal of our study was to investigate the overall increasing trend of arrowtooth flounder in the EBS at a finer spatial resolution to better understand the potential spatial variability in their predatory impact under a changing climate. The specific objectives were to determine whether arrowtooth flounder were increasing equally throughout the EBS and, if not, (1) identify areas with dissimilar abundance trends and (2) explore physical and biological habitat characteristics that may be contributing to these differences. We used a 26 yr fishery-independent survey time series of arrowtooth catch per unit effort (CPUE) at individual bottom trawl stations on the

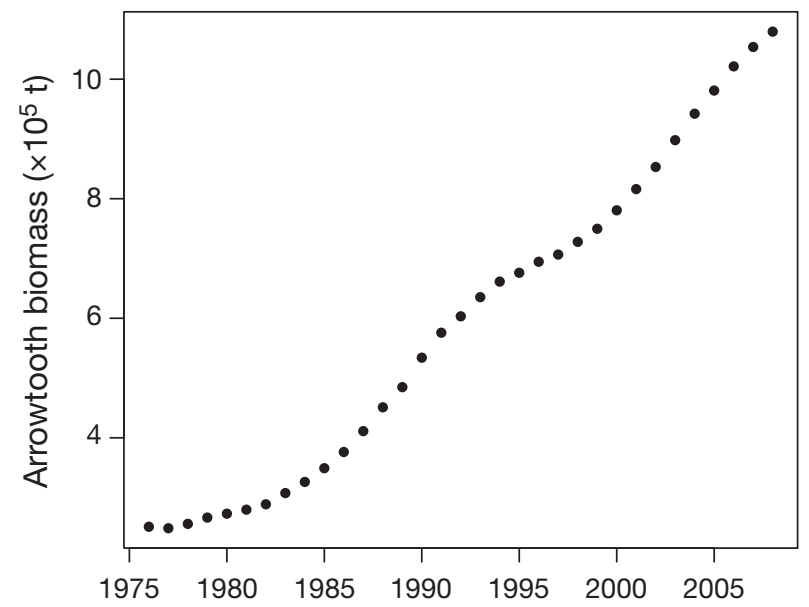

Fig. 2. Atheresthes stomias. Stock assessment estimates of age-1+ arrowtooth flounder total biomass (t) from Wilderbuer et al. (2009) 
EBS shelf to analyze abundance trends at fine spatial scales (37.04 km grid squares). Stations were grouped based on similarities in relative arrowtooth abundance trends rather than a priori by domains defined by hydrographic structure and currents associated with characteristic bottom depth ranges that are commonly used for other studies in the EBS (Schumacher \& Stabeno 1998, Hunt et al. 2002). We tested the hypothesis that physical habitat characteristics may influence annual arrowtooth distribution by modeling the effect of bottom temperatures and depths on their presence or absence at trawl stations. Furthermore, because temperature and depth may influence not only arrowtooth presence in trawls, but the amount caught, we modeled their effect on the non-zero catch rates. We also tested the hypothesis that differences in biological habitat characteristics influence arrowtooth abundance trends by examining stomach contents of arrowtooth caught at trawl stations. Finally, we discuss how the results of the fine-scale analysis of arrowtooth abundance trends compare with those previously reported for largerscale analyses and the implications of these findings for the management of groundfish stocks.

\section{MATERIALS AND METHODS}

\section{Data collection}

Arrowtooth CPUE (in total $\mathrm{kg} \mathrm{ha}^{-1}$ ) and diet were estimated from standard annual bottom trawl surveys conducted by the National Marine Fisheries Service along the EBS shelf between 1982 and 2007 (Acuna \& Lauth 2008). The surveys occurred during summer, starting between late May and early June and ending in late July or early August. The survey area was designed with fixed stations on a $20 \times 20 \mathrm{n}$ mile $(37.04 \times$ $37.04 \mathrm{~km}$ ) grid that ranged in depth from 50 to $200 \mathrm{~m}$ from the Alaska Peninsula north to approximately the latitude of St. Matthew Island $\left(60^{\circ} 50^{\prime} \mathrm{N}\right)$. Because the EBS shelf survey is a combined shellfish and groundfish survey, the station density increases in areas of high historical crab abundance around the Pribilof Islands and St. Matthew Island. Survey trawl sampling began each year in the eastern portion of the EBS shelf in Bristol Bay. Stations were sampled along alternate longitudinal columns by 2 chartered trawl vessels proceeding westward to the EBS shelf edge (see Figs. 1 \& 3). Both vessels used standard 83-112 Eastern otter trawls with $25.3 \mathrm{~m}$ headropes and $34.1 \mathrm{~m}$ footropes. Survey tows at each station lasted 30 min at 3 knots.
For each tow, the catch was sorted to species, and the weight, number, and length of each species caught, including arrowtooth, were recorded (Acuna \& Lauth 2008). Catches estimated to be less than $1150 \mathrm{~kg}$ were enumerated entirely. Larger catches were subsampled, and measurements were extrapolated to the total catch. Bottom temperature and depth were also recorded on each tow using a Sea-Bird SBE-39 datalogger (Sea-Bird Electronics). Additional biological data were collected for commercially important and numerically abundant species. For arrowtooth, these included contents from stomachs collected opportunistically, leading to an unequal distribution in sampling effort during the study years. In total, the contents of 2040 large $(\geq 40 \mathrm{~cm})$ and 1978 small $(<40 \mathrm{~cm})$ arrowtooth stomachs were examined for this study. Large arrowtooth are approximately age $\geq 6$ yr (T. Wilderbuer pers. comm.). Maturity data from the adjacent Gulf of Alaska indicate that $50 \%$ of female arrowtooth are sexually mature at age $7 \mathrm{yr}$ and at $46 \mathrm{~cm}$ in length (Stark 2008). Specimens that displayed evidence of regurgitation or feeding while caught in the net were excluded from the samples. Empty stomachs were noted, and in non-empty stomachs, lengths and weights of fish prey were recorded.

\section{Cluster analysis}

To test for spatial differences in abundance trends, arrowtooth CPUE time series at trawl stations were clustered based on similarity in relative abundance through time using the methods of Cope \& Punt (2009). This hierarchical k-medoids clustering approach uses yearly CPUE as the multivariate clustering metric by which areas with similar relative CPUE across time are clustered together. CPUE were assumed to reflect local arrowtooth abundance (e.g. within ca. $18.52 \mathrm{~km}$ of a station). Prior to clustering, individual stations that were not surveyed in all years were excluded, leading to 235 stations (out of 356) with the complete 26 yr time series. In order to distinguish stations appropriate for developing arrowtooth CPUE measures (thus avoiding stations with historically low arrowtooth presence), additional data filtering was performed using 2 decision rules: stations were removed (1) if the total log-transformed CPUE summed over $26 \mathrm{yr}$ was $<1 \mathrm{~kg} \mathrm{ha}^{-1}$ or (2) if the total log-transformed CPUE was $<4 \mathrm{~kg} \mathrm{ha}^{-1}$ and there were fewer than $4 \mathrm{yr}$ with non-0 CPUE. The final 201 stations were used in the clustering algorithm. 


\section{Physical habitat analysis}

Differences in mean depth and temperature among clusters were compared using general linear mixed models (GLMMs) with year specified as a random effect to account for the repeated measures over time at individual stations. Analyses were conducted using the R (R Development Core Team 2009) package 'Imer' (Bates \& Maechler 2010). In the case of depth, the random effect was negligible (variance < 0.001 ), so analysis of variance (ANOVA) was used for the final analysis. Plots revealed no correlation between bottom temperature and depth variables within each cluster.

GLMMs were used to investigate the influence of temperature and depth on arrowtooth CPUE trends within each cluster using a 2-step process (Helser et al. 2004). First, GLMMs were used to model the presence or absence of arrowtooth in survey trawls specifying binomial error distribution. Separate models were developed for each cluster with bottom temperature and/or depth entered as main effects. Candidate models were fit with the adaptive GaussianHermite quadrature (AGQ) approximation to the log-likelihood. nAGQ indicates the number of points per axis at which the approximation stabilized for the greatest accuracy in evaluating the log-likelihood. Models were run by increasing nAGQ until the estimates stabilized. Fits were compared using Akaike information criteria (AIC), and the top 2 models were tested for significant differences using a chi-squared test when differences in AIC values were $<1$ (Crawley 2007).

Second, GLMMs were used to model the CPUE of arrowtooth in trawls with non-zero catch rates. Lognormal error distributions for the non-zero catch rates were chosen based on plots that indicated that the variance was proportional to the square of the mean catch rate (reviewed by Brynjarsdottir \& Stefansson 2004). The models were fit using log-likelihood, and the model with the best fit to the data was chosen using AIC. Year was specified as a random effect in all models to account for annually repeated surveys at trawl stations. Generalized additive models were explored, but no evidence of substantial non-linearity in the smoothed terms was found.

\section{Diet analysis}

Stomach samples were analyzed separately for large and small arrowtooth. Stomachs were noted to be empty or not and grouped by decade within clus- ter both to increase sample sizes and to reduce the signal noise produced by annually varying sample sizes. Total percent frequency of occurrence of pollock and non-pollock fish prey was calculated for each cluster and each decade for all large arrowtooth. Based on pollock age data from the Alaska Fisheries Science Center (AFSC) Age and Growth Program (unpubl. data), age-length keys for pollock prey in large arrowtooth were developed specific to each decade and each cluster because pollock lengths-at-age have been shown to vary temporally and spatially along a north-south axis in the EBS (Ianelli et al. 2007, Stahl \& Kruse 2008). The total percent frequency of occurrence of pollock by age class was calculated using the same age-length keys.

\section{RESULTS}

Visual inspection of annual CPUE at survey stations indicated that while total arrowtooth abundance increased in the EBS from 1982 to 2007, smaller-scale regions within the EBS contributed unequally to this trend (Fig. 3). In particular, in the early years of the time series (e.g. 1983), localized centers of higher abundance occurred along the northwestern near shelf-edge region near Zhemchug Canyon and in the southernmost near shelf-edge region. Arrowtooth abundance decreased eastward, and they were absent in trawls farther than $200 \mathrm{~km}$ from the shelf break except for a few $\left(<1.8 \mathrm{~kg} \mathrm{ha}^{-1}\right)$ in the southeast region extending toward Bristol Bay. Throughout the 1980s, arrowtooth abundance increased in magnitude and extent around the 2 centers of abundance in the northwest and southern regions. This pattern continued in later years concomitant with annual variations in the eastward (and shallower) extent of their distribution, negatively correlated $(\mathrm{r}=-0.47, t=-2.60, \mathrm{df}=24, \mathrm{p}=0.02)$ to the geographic extent of the pool of cold bottom water on the shelf. Few arrowtooth were caught at stations where bottom temperatures were $\leq 0^{\circ} \mathrm{C}$ and bottom depth was $\leq 50 \mathrm{~m}$.

Clustering of CPUE trends at individual trawl stations resulted in 4 similar-sized groups showing stable, increasing, and variable trends (Table 1, Fig. 4). Three of the 4 clusters (W, E, and N) were spatially aggregated (Fig. 5); the remaining cluster included stations that ranged from the northern to the southern boundaries of the study area. These we subdivided latitudinally into a northwestern (NW) and southeastern (SE) cluster to feature the 2 spatial aggregations found within the cluster. 

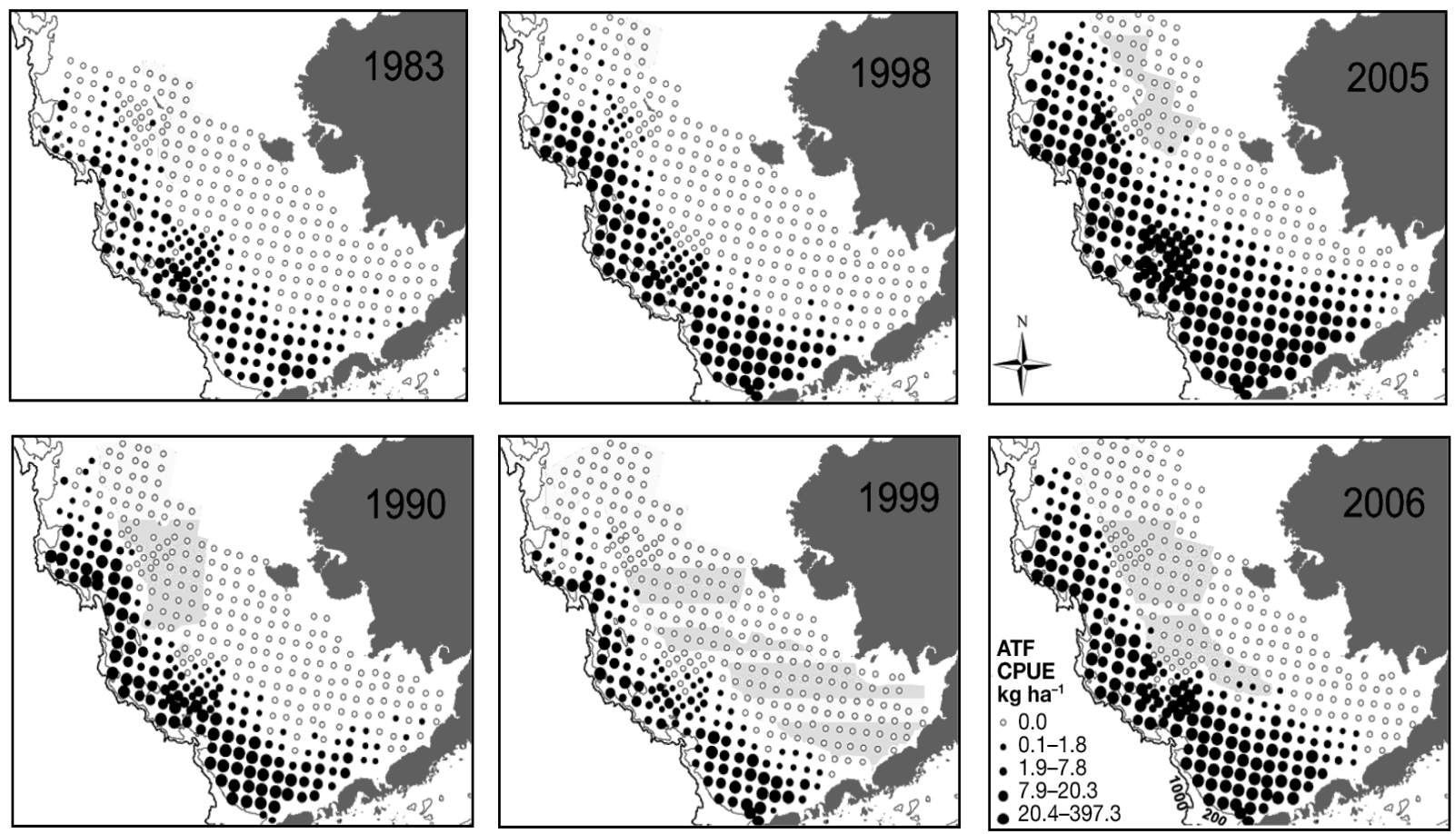

Fig. 3. Atheresthes stomias. Arrowtooth flounder catch per unit effort $\left(\mathrm{kg} \mathrm{ha}^{-1}\right)$ at trawl survey stations on the eastern Bering Sea shelf during select warm $(1983,1998,2005)$, intermediate $(1990)$, and cold $(1999,2006)$ years. Bottom water temperatures $<0^{\circ} \mathrm{C}$ are indicated by gray shading

Table 1. Atheresthes stomias. Number of trawl survey stations assigned to each cluster, excluding outliers, and characteristics of arrowtooth flounder catches in each cluster. Mean lengths (in mm) of arrowtooth are from 1982 to 2007

\begin{tabular}{|lccc|}
\hline Cluster & $\begin{array}{c}\text { No. } \\
\text { stations }\end{array}$ & $\begin{array}{c}\text { \% station-years } \\
\text { with 0 arrowtooth }\end{array}$ & $\begin{array}{c}\text { Mean length } \\
\pm \text { SD }\end{array}$ \\
\hline W & 62 & 1.8 & $389 \pm 115$ \\
E & 42 & 68.1 & $353 \pm 101$ \\
NW & 13 & 30.0 & $510 \pm 106$ \\
SE & 40 & 21.9 & $366 \pm 107$ \\
N & 38 & 40.4 & $394 \pm 122$ \\
\hline
\end{tabular}

Clusters $\mathrm{W}, \mathrm{E}$, and $\mathrm{N}$ each contained 2 geographically distinct outliers, defined as stations that are $>130 \mathrm{~km}$ from at least $95 \%$ of stations within that cluster. Outliers were excluded from further analyses based on the assumption that physical and biological habitat influences that we investigated do not operate at such a fine scale that CPUE trends at these stations would be distinct from the surrounding stations.

Abundance trends at stations in the W cluster were most distinct from the remaining stations, showing increases in early years followed by generally stable trends in abundance from the late 1980s to 2007, when mean catch rates were $30.1 \pm 23.3 \mathrm{~kg} \mathrm{ha}^{-1}$ (Fig. 4). In this cluster, arrowtooth were almost always caught in survey trawls $(98.2 \%$ of stationyears; Table 1). In contrast, stations in the E cluster had consistently low arrowtooth abundances with the exception of notably higher abundances from 2003 to 2005 (Fig. 4). Bottom trawls at these stations often caught no arrowtooth (Table 1). Stations in the NW and SE clusters showed annually variable trends in abundances with a generally increasing trend, whereas stations in the N cluster showed annual fluctuations between zero and non-zero values (Fig. 4). These latter 3 clusters also showed notably higher abundances from 2003 to 2005, with the trend extending to 2006 in the SE cluster and to 2007 in the NW cluster. Arrowtooth were caught in trawls in 59.6 to $78.1 \%$ of station-years in these 3 clusters.

The length distribution of arrowtooth caught in trawls varied temporally and spatially. The mean length of arrowtooth caught at stations in the NW cluster was larger than those in other clusters $(F=$ 262, 200; df $=5 ; \mathrm{p}<0.001$; Table 1). In fact, small arrowtooth $<100 \mathrm{~mm}$ appeared in the NW cluster only in the last year of the time series. The $\mathrm{W}$ cluster showed the broadest range in lengths across years. Small arrowtooth $<100 \mathrm{~mm}$ were most frequently 


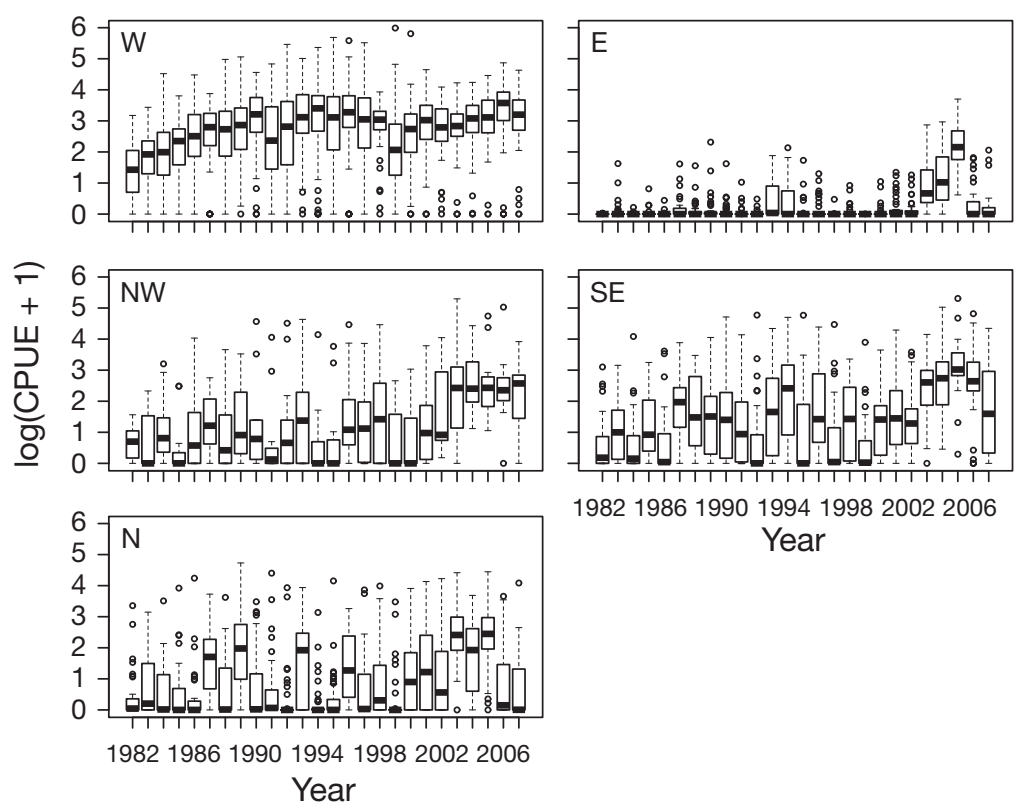

Fig. 4. Atheresthes stomias. Arrowtooth flounder scaled catch per unit effort (CPUE, $\mathrm{kg} \mathrm{ha}^{-1}$ ) data at individual trawl stations on the eastern Bering Sea shelf. Data are grouped by cluster assignment. Thick bars, boxes, and whiskers represent medians, quartiles, and 1.5 quartile ranges, respectively. Circles are outliers beyond the 1.5 quartile range

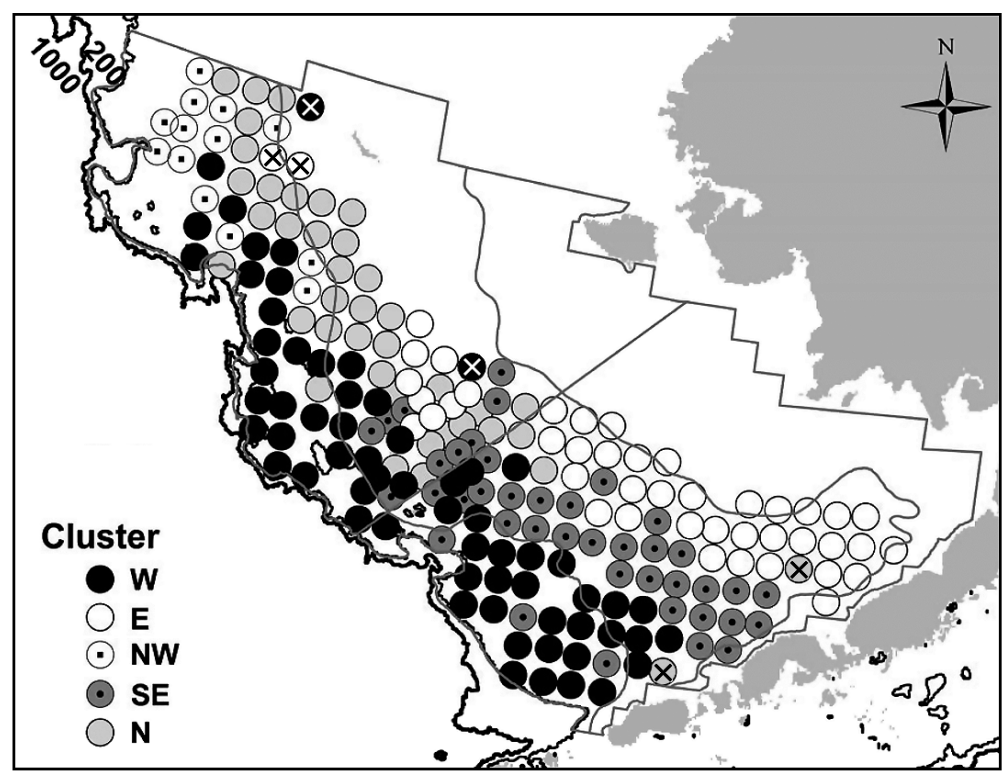

Fig. 5. Final cluster assignments for trawl stations based on 26 yr time series of arrowtooth flounder catch per unit effort trends on the eastern Bering Sea shelf. Grey lines indicate survey station groupings used by Acuna \& Lauth (2008). x: outliers that were excluded from analysis

\section{Physical habitat}

Mean bottom temperatures varied among most clusters (Tukey contrasts: $\mathrm{p}<0.001$; Fig. 6); differences in mean temperatures between the NW and E clusters ( $p=0.94$ ) and between the NW and N clusters ( $p=0.15$ ) were not statistically significant. Bottom temperatures were highest at stations in the $\mathrm{W}$ cluster $\left(3.6^{\circ} \mathrm{C} \pm 0.8 \mathrm{SD}\right)$ relative to stations in other clusters (range in means 1.9 to $2.6^{\circ} \mathrm{C}$ ). Mean bottom depths also varied by cluster (Fig. 6; $F=1491 ;$ df $=4$, 4316; $\mathrm{p}<0.001)$. Post hoc comparisons showed that mean depths among all clusters differed significantly (Tukey contrasts: $\mathrm{p}<0.001$ ). Bottom trawls at stations in the E cluster were most shallow $(64 \pm 7 \mathrm{~m})$, and deepest in the W cluster $(115 \pm 21 \mathrm{~m})$ and NW cluster $(130 \pm 17 \mathrm{~m})$.

Best-fit models for explaining arrowtooth presence in trawls included both bottom temperature and depth variables in all but the NW cluster (Table 2). The best model for stations in this cluster included only bottom temperature, although this model was not significantly different $(p=0.16)$ from the 2factor model $(\triangle \mathrm{AIC}=0.03)$. Both increasing temperature and depth explained higher proportions of trawls containing arrowtooth. The effect of temperature on the presence of arrowtooth was greatest in the NW cluster. For all but the temperature-only model for the NW cluster, $\triangle \mathrm{AIC}$ values for the next best models were $\geq 8.4$, indicating that the single-factor models had little support for explaining the data (Burnham \& Anderson 2002).

Best-fit models for explaining nonzero catch rates of arrowtooth included both bottom temperature and depth for all clusters (Table 3). The single-factor models had essentially no support as indicated by $\triangle \mathrm{AIC}$ values $\geq 36$ (Burnham \& Anderson 2002). Increasing tempera-

caught in the W and SE clusters, both in the southern shelf region. Large arrowtooth $>700 \mathrm{~mm}$ were not caught in the E cluster, the shallowest and easternmost cluster. ture and depth were associated with higher catch rates in all clusters. Model residuals indicated reasonable fits to the expectations of lognormal error distributions. 
Table 2. Fixed parameter estimates for best-fitting binomial general linear models of arrowtooth flounder presence in trawls in relation to bottom temperature $\left({ }^{\circ} \mathrm{C}\right)$ and depth $(\mathrm{m})$ within each cluster. Depth is recorded inversely, i.e. a larger value denotes a deeper depth. Candidate models were fit with the adaptive Gaussian-Hermite approximation to the log-likelihood. nAGQ indicates the number of points per axis at which the approximation stabilized for the greatest accuracy in evaluating the log-likelihood. The top 2 models were compared using the likelihood ratio test

\begin{tabular}{|lcccccr|}
\hline Cluster & $\begin{array}{c}\text { Bottom } \\
\text { temperature }\end{array}$ & $\mathrm{p}$ & $\begin{array}{c}\text { Bottom } \\
\text { depth }\end{array}$ & $\mathrm{p}$ & $\begin{array}{c}\text { Random } \\
\text { variance }\end{array}$ & nAGQ \\
\hline $\mathrm{W}$ & 0.581 & 0.002 & 0.079 & $<0.001$ & 0.287 & 10 \\
$\mathrm{E}$ & 1.535 & $<0.001$ & 0.127 & $<0.001$ & 2.599 & 6 \\
$\mathrm{NW}^{\mathrm{a}}$ & 2.587 & $<0.001$ & - & - & 0.861 & 8 \\
$\mathrm{SE}$ & 2.082 & $<0.001$ & 0.112 & $<0.001$ & 1.433 & 8 \\
$\mathrm{~N}$ & 1.886 & $<0.001$ & 0.016 & 0.001 & 0.716 & 8 \\
anot significantly different from the full model $(\mathrm{p}=0.16)$. We present the \\
\multicolumn{7}{l}{ simpler model } \\
\hline
\end{tabular}

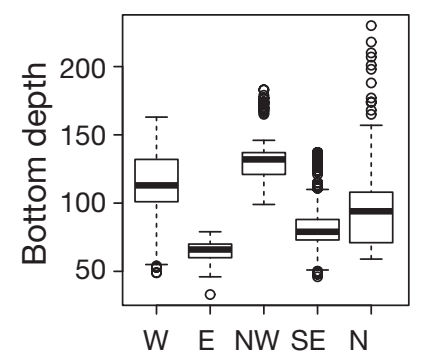

Fig. 6. Median and quantiles of bottom temperature and depths recorded at stations grouped by cluster assignment

Table 3. Akaike information criterion (AIC) values for general linear models with log-normally distributed error and fit with maximum likelihood. All models test the effects of bottom temperature $\left({ }^{\circ} \mathrm{C}\right)$, bottom depth (in $\mathrm{m}$ ), or both on nonzero catch rates (catch per unit effort) of arrowtooth flounder at stations within clusters from 1982 to 2007

\begin{tabular}{|lccrc|}
\hline Cluster & $\begin{array}{c}\text { Bottom } \\
\text { temperature }\end{array}$ & $\begin{array}{c}\text { Bottom } \\
\text { depth }\end{array}$ & $\Delta$ AIC & $\begin{array}{c}\text { Random } \\
\text { variance }\end{array}$ \\
\hline W & 0.533 & 0.017 & 155 & 0.375 \\
E & 0.818 & 0.089 & 42 & 1.300 \\
NW & 1.634 & 0.027 & 36 & 0.618 \\
SE & 1.046 & 0.027 & 87 & 0.884 \\
N & 1.286 & 0.031 & 176 & 0.407 \\
\hline
\end{tabular}

\section{Biological habitat}

The greatest number of stomachs was collected at stations in the W cluster $(\mathrm{n}=1204$ from large arrowtooth; $\mathrm{n}=1325$ from small arrowtooth) and the fewest at stations in the E cluster ( $\mathrm{n}=57$ large; $\mathrm{n}=56$ small). The numbers of stomachs collected each decade at stations in the remaining clusters ranged from 242 to
283 for large and 36 to 443 for small arrowtooth. Fewer stomachs were collected during the 1980s $(\mathrm{n}=913)$ than in the 1990s and 2000s ( $\mathrm{n}=1572$ and 1533, respectively), where sample sizes ranged across decades from 307 to 937 and 606 to 727 for large and small arrowtooth, respectively.

With few exceptions, at least half of the stomachs collected at stations in clusters with > 30 samples in a decade were empty (Table 4). The lowest incidences of empty stomachs for both sizes of arrowtooth were found in the NW cluster during the 2000s, where only $16 \%$ of stomachs from large and $13 \%$ from small arrowtooth were empty. During the 1990s, the percentages of empty stomachs in large arrowtooth collected in the NW and N clusters were also low (27 and $45 \%$, respectively). There were too few stomachs collected from the E cluster during the 1980s to include in comparisons. In contrast, in the W cluster, where the greatest number of stomachs was collected, 64 to $77 \%$ of large and 71 to $81 \%$ of small arrowtooth were empty across decades. All of the 20 large arrowtooth collected at stations in the SE cluster during the 1980s had empty stomachs.

In most cases, pollock were the most common fish prey item of large arrowtooth collected from stations in each cluster (Table 5). The only time when nonpollock prey outnumbered pollock occurred during the 2000s in the E cluster. Individual stomachs contained up to 6 fish prey, with an average of $1.17 \pm$ 0.48 per non-empty stomach. Pollock and other species of fish were not found together in the same stomach. Age-1 pollock were found most frequently relative to other aged pollock in all clusters and decades (discounting the E cluster during the 1980s, when only 2 stomachs were collected), although age- 2 pollock were more common in the NW cluster during the 1990s (Fig. 7). Age-0 and age-4+ pollock were found infrequently in arrowtooth stomachs, although age-4+ were present in increasing frequency across decades in the $\mathrm{W}$ cluster. This was the only cluster in which age-4+ pollock were found in the earliest decade, but by the 2000s, they were found in stomachs from all clusters. In contrast, age- 0 pollock were found in decreasing frequency across decades in the $\mathrm{N}$ cluster.

Eelpouts (Lycodes and Zoarcidae spp.) comprised 50 to $94 \%$ of the non-gadoid, identifiable prey across decades in the $\mathrm{W}$ cluster. They were among the most 
Table 4. Atheresthes stomias. Percent of empty arrowtooth flounder stomach samples collected by decade and grouped by cluster assignment. Numbers in parentheses represent the total number of stomach samples

\begin{tabular}{|c|c|c|c|c|c|c|}
\hline \multirow{2}{*}{ Cluster } & & \multirow{2}{*}{$\begin{array}{c}\geq 40 \mathrm{~cm} \\
1990 \mathrm{~s}\end{array}$} & \multirow[b]{2}{*}{$2000 \mathrm{~s}$} & \multirow[b]{2}{*}{$1980 \mathrm{~s}$} & \multirow{2}{*}{$\begin{array}{l}<40 \mathrm{~cm} \\
1990 \mathrm{~s}\end{array}$} & \multirow[b]{2}{*}{$2000 \mathrm{~s}$} \\
\hline & $1980 \mathrm{~s}$ & & & & & \\
\hline W & 77 (209) & 70 (599) & 64 (396) & $81(434)$ & 78 (465) & $71(426)$ \\
\hline $\mathrm{E}$ & $0(2)$ & $41(22)$ & $61(33)$ & $100(1)$ & $67(6)$ & 76 (49) \\
\hline NW & $69(32)$ & 45 (96) & 16 (114) & 46 (13) & $57(7)$ & 13 (16) \\
\hline SE & $100(20)$ & 72 (123) & 66 (140) & 77 (124) & 87 (123) & 73 (196) \\
\hline $\mathrm{N}$ & $70(44)$ & 27 (97) & 54 (113) & $65(34)$ & $50(34)$ & $64(50)$ \\
\hline
\end{tabular}

Table 5. Atheresthes stomias. Frequency of occurrence of pollock and other fish in non-empty stomachs of large $(\geq 40 \mathrm{~cm})$ arrowtooth flounder

\begin{tabular}{|lcccc|}
\hline Prey & Cluster & $1980 \mathrm{~s}$ & $1990 \mathrm{~s}$ & $2000 \mathrm{~s}$ \\
\hline Pollock & $\mathrm{W}$ & 0.65 & 0.88 & 0.70 \\
& $\mathrm{E}$ & 0.50 & 0.85 & 0.38 \\
& $\mathrm{NW}$ & 0.70 & 0.92 & 0.91 \\
& $\mathrm{SE}$ & & 0.80 & 0.87 \\
Other & $\mathrm{N}$ & 1.00 & 0.96 & 0.96 \\
& $\mathrm{~W}$ & 0.35 & 0.12 & 0.30 \\
& $\mathrm{E}$ & 0.50 & 0.15 & 0.62 \\
& $\mathrm{NW}$ & 0.30 & 0.08 & 0.09 \\
& $\mathrm{SE}$ & & 0.20 & 0.13 \\
& $\mathrm{~N}$ & 0.00 & 0.04 & 0.04 \\
\hline
\end{tabular}

common non-pollock prey in stomachs collected from the NW, SE, and N clusters. Sand lance Ammodytes hexapterus were the most common prey item in the $\mathrm{E}$ cluster, although all but one were from 2 stomachs collected from a single haul (3 in one stomach, 2 in the other), and capelin Mallotus villosus were found only in stomachs in this cluster. During the 2000s, shrimp (Pandalus and Pandalopsis spp.) appeared in arrowtooth stomachs from all clusters except the SE cluster.

\section{DISCUSSION}

The overall increase in arrowtooth abundance in the EBS has been well documented in annual stock assessments (Wilderbuer et al. 2009) and peerreviewed literature (Hunt et al. 2002, Spencer 2008). We were interested in which areas within the EBS arrowtooth were increasing and which were stable, and this motivated clustering CPUE estimates from individual survey stations. In stock assessments, the CPUE estimates used to model the abundance trends were summarized spatially using station groupings not specific to arrowtooth, but designed to best reflect habitat associations for multiple groundfish species (Acuna \& Lauth 2008). The 6 groups are bounded by the 50,100, and $200 \mathrm{~m}$ isobaths and divided into northwest and southeast portions (Fig. 6). Clustering arrowtooth CPUE at individual survey stations revealed patterns not seen when station groupings were defined a priori. In particular, analyzing CPUE trends at the scale of individual survey stations in this study

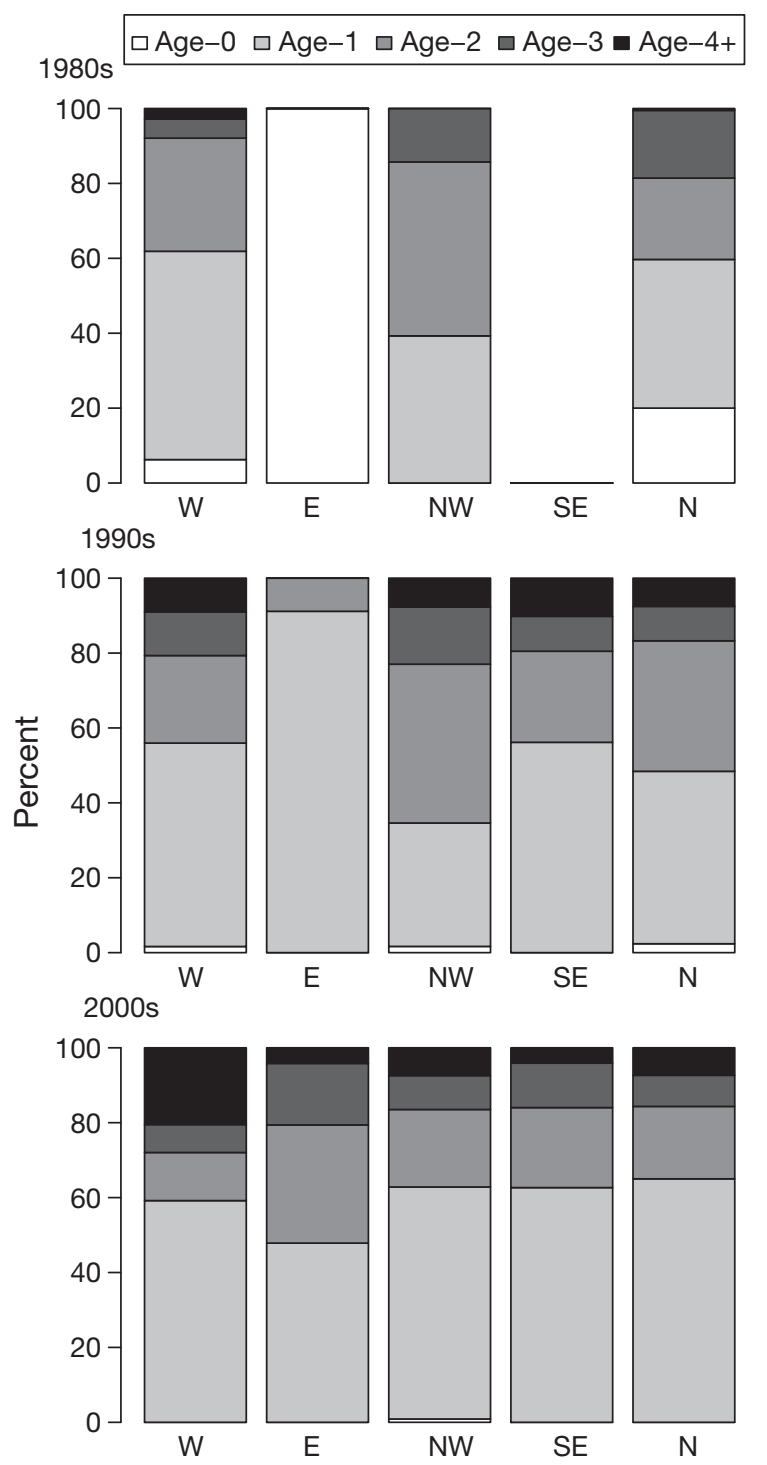

Fig. 7. Atheresthes stomias. Total percent frequency of occurrence of walleye pollock by age class in large $(\geq 40 \mathrm{~cm})$ arrowtooth flounder stomachs collected in each cluster during the 1980s (top), 1990s (middle), and 2000s (bottom) 
rather than at the group level used in previous studies revealed that abundances have generally not increased in the most densely inhabited region, which are the stations in the W cluster in this study, and that other regions are likely contributing more to the overall increase.

In fact, abundances in the $\mathrm{W}$ cluster along the shelf break have remained stable for $\geq 20 \mathrm{yr}$, as has the broad length-class distribution of arrowtooth caught in survey trawls. The two together suggest stability in arrowtooth populations in this region at least from the 1990 s to the present. Stations in this region are close to the shelf break and the presumed spawning areas in the deep waters of the southern end of the continental slope. Indeed, small arrowtooth $<100 \mathrm{~mm}$ were most frequently found in the $\mathrm{W}$ and SE clusters, comprising the stations closer to the spawning region relative to those of other clusters.

Arrowtooth movement patterns and geographic distribution appear to be strongly driven by temperature, and specifically the location of the cold pool and $0^{\circ} \mathrm{C}$ water. All clusters except the $\mathrm{W}$ cluster showed increases in CPUE during the summers of 2003 to 2005. These were years when the summer extent of the cold pool of bottom water on the EBS shelf was much reduced. This cold pool forms annually, influenced by the variable extent of the sea ice cover from the previous winter (Stabeno et al. 2001), and can serve as a physical habitat barrier based on thermal preferences. The relatively large interannual fluctuations in bottom temperature influence the spatial and temporal distribution of groundfishes and the structure and ecology of the marine community on the EBS shelf (Kotwicki et al. 2005, Mueter \& Litzow 2008, Spencer 2008). Community-wide northward distribution shifts of fish and invertebrates in the EBS have been linked in part to the northward retreat of the cold pool (Mueter \& Litzow 2008). Shifts in geographic distributions of other groundfish have been more closely linked to density-dependent processes rather than changes in environmental conditions (Swain \& Wade 1993, Swain \& Benoit 2006). Indeed, arrowtooth population expansion to the middle of the EBS shelf was demonstrated to occur with increases in abundance, suggesting density-dependent habitat selection, but this shift was found to be more strongly related to the reduction in the cold pool during warm years (Spencer 2008).

During the warm years of 2003 to 2005, abundances increased away from the shelf edge, suggesting that there was movement of arrowtooth onto shelf areas often covered by the cold pool. However at the same time, abundances along the shelf edge (the W cluster) did not decline. Instead, data from trawl surveys in deeper water along the EBS slope during a warm (2004) and 2 cold years $(2002,2008)$ indicate that there was a general shift of arrowtooth CPUE from deeper slope habitat (400 to $800 \mathrm{~m}$ ) to shallower habitat during the warm years and the opposite trend in cold years; abundances remained relatively constant or increasing at the near-shelf edge stations of the W cluster to slope stations at $400 \mathrm{~m}$ (AFSC unpubl. data). This was also the only cluster where the median CPUE was above 0 during 1999, an exceptionally cold year.

Much of the recent increase in total abundance appears to be driven by the increase in larger arrowtooth caught at stations in the most northwestern region of the study area, the NW cluster. Mean lengths of arrowtooth here are larger relative to other clusters, influenced in part by the lack of small arrowtooth in this region. The smaller percentage of empty stomachs relative to those collected in other clusters suggests that arrowtooth at these stations became more successful predators during the 2000s. The proportionally greater biomass of large arrowtooth in the NW cluster also suggests the possibility of relatively higher predation pressure on pollock in this region. Age-3+ pollock increased in the diet in the 1990s, when the total percent of stomachs containing prey increased and the percent frequency of other fish prey in stomachs decreased.

Conversely, arrowtooth caught in the SE cluster had the highest and near highest proportions of empty stomachs for the large and small size classes, respectively. However, the SE cluster also showed a marked increase in abundance during later, warmer, years (2003-2005), indicating possible increased physical habitat suitability, agreeing with the findings of Spencer (2008). The high numbers of small arrowtooth found in this area suggest that this region may be a nursery area (along with the W cluster). Although little is known about arrowtooth recruitment dynamics, a drift modeling study by Wilderbuer et al. (2002) found that during the 1980s, eastern wind-driven advection of flatfish larvae from the presumed spawning grounds, towards and through the SE cluster, was found to coincide with years of good recruitment. In contrast, more westerly advection during the 1990s, biased towards the W cluster, coincided with years of poor recruitment.

The easternmost clusters farthest from the shelf break, the $\mathrm{E}$ and $\mathrm{N}$ clusters, contribute variability to the overall EBS arrowtooth abundance trends. While the E cluster seems to be more marginal habitat as suggested by lower abundances, both regions are 
within the variable extent of the cold pool, and therefore are occupied to a lesser extent during the years when the cold pool encompasses a greater area (Spencer 2008). In terms of biological habitat, sand lance was the most common non-pollock prey in the E cluster, which is also the shallowest of clusters. This agrees with findings in the Gulf of Alaska, where sand lance appear to be a locally important prey of arrowtooth flounder in the shallow waters and where sand lance were noticeably more important in the diets of the larger arrowtooth, compared to smaller cohorts, in the shallow depths (Knoth \& Foy 2008).

In general, arrowtooth appear to be less successful predators in the EBS than in the GOA. The percentage of stomachs collected from triennial GOA surveys between 1993 and 1999 containing prey ranged between 47 and $76 \%$ each year (Yang \& Nelson 2000). In the western GOA, Knoth \& Foy (2008) found that $63 \%$ of arrowtooth stomach samples contained prey. Similar proportions of stomachs with prey occurred infrequently in the EBS. Only in arrowtooth collected in the $\mathrm{N}$ cluster during the 1990s and large arrowtooth collected in the NW cluster during the 1990s and 2000s were proportions of empty stomachs similar to those in the GOA (for $\mathrm{n}>30$ stomachs samples per decade and size class). These results may further hint at density dependence or may just reflect differences in the prey field for arrowtooth from each region.

Favorable physical habitat (deep and warm) and diet trends (full stomachs) suggest that arrowtooth in the NW cluster in the EBS have the potential to increase further, or at least to the density seen in the $\mathrm{W}$ cluster $\left(30.1 \pm 23.3 \mathrm{~kg} \mathrm{ha}^{-1}\right)$ where they may have reached carrying capacity. Although recent years (2006-2010) have been cold, and are years of decreased arrowtooth abundance, climate models predict further warming in the EBS (Overland \& Stabeno 2004). Given the positive relationship of geographic range of arrowtooth to temperature as well as indications of density dependence, we predict that arrowtooth should expand their distribution and abundance as the EBS warms. In the past, periods of cold climate conditions alternating with warm conditions may have limited the potential for the arrowtooth population to expand beyond the shelf edge and slope. During years of large cold pools, the restricted distribution of arrowtooth may have enhanced density-dependent regulation and curtailed population growth. If the periodic expansions of the cold pool become less frequent with a generally warming climate, then arrowtooth density may increase across much of the shelf.

Furthermore, with little current commercial fisheries pressure, we further predict that arrowtooth- induced mortality of pollock will increase along with arrowtooth abundance. 'Refuges' for age-1 pollock presently at and near the cold pool may cease to exist if arrowtooth densities increase during periods of reduced cold pools. Increased market suitability with new food-grade additives that improve the texture of arrowtooth to allow for surimi and fillet production (Hiatt et al. 2009) may increase fishery pressure on arrowtooth. However, that pressure will likely be limited by halibut bycatch limits and an overall 2 million metric ton cap on annual groundfish removals in the EBS, which rewards fishing on higher-value targets (NPFMC 2010a). EBS groundfish community structure will also be influenced by trends in pollock abundance through pollock cannibalism and adult pollock predation pressure on juvenile arrowtooth.

Acknowledgements. We thank B. Lauth and G. Lang for providing survey and diet data. G. Hunt, M. Dorn, and A. Punt provided valuable input. G. Hunt, K. Bailey, S. Gaichas, and P. Spencer provided helpful comments on earlier drafts. The comments of 3 anonymous reviewers helped to improve the manuscript. This research was performed while S.G.Z. held a National Research Council Research Associateship Award at the Alaska Fisheries Science Center.

\section{LITERATURE CITED}

Acuna E, Lauth RR (2008) Results of the 2007 Eastern Bering Sea continental shelf bottom trawl survey of groundfish and invertebrate resources. NOAA Tech Memo NMFSAFSC-181. US Department of Commerce, Seattle, WA

Bates D, Maechler M, Bolker B (2010) lme4: linear mixedeffects models using $\mathrm{S} 4$ classes. $\mathrm{R}$ package version 0.999375-33. http://CRAN.R-project.org/package=lme4

Brynjarsdottir J, Stefansson G (2004) Analysis of cod catch data from Icelandic groundfish surveys using generalized linear models. Fish Res 70:195-208

Burnham KP, Anderson DR (2002) Model selection and multimodel inference: a practical information-theoretic approach, 2nd edn. Springer, New York, NY

Ciannelli L, Fauchald P, Chan KS, Agostini VN, Dingsor GE (2008) Spatial fisheries ecology: recent progress and future prospects. J Mar Syst 71:223-236

Cope JM, Punt AE (2009) Drawing the lines: resolving fishery management units with simple fisheries data. Can J Fish Aquat Sci 66:1256-1273

Crawley MJ (2007) The R book. John Wiley and Sons, Chichester

Helser TE, Punt AE, Methot RD (2004) A generalized linear mixed model analysis of a multi-vessel fishery resource survey. Fish Res 70:251-264

Hiatt T, Dalton M, Felthoven R, Garber-Yonts B and others (2009) Economic status of the groundfish fisheries off Alaska, 2008. In: 2009 North Pacific groundfish stock assessment and fishery evaluation reports for 2010. North Pacific Fishery Management Council, Anchorage, AK 
Hunt GL Jr, Stabeno P, Walters G, Sinclair E, Brodeur RD, Napp JM, Bond NA (2002) Climate change and control of the southeastern Bering Sea pelagic ecosystem. DeepSea Res II 49:5821-5853

Ianelli JN, Barbeaux S, Honkalehto T, Kotwicki S, Aydin KY, Williamson N (2007) Eastern Bering Sea walleye pollock. In: 2008 stock assessment and fishery evaluation reports for the groundfish resources of the Bering Sea/Aleutian Islands regions. North Pacific Fishery Management Council, Anchorage, AK

Ianelli JN, Barbeaux S, Honkalehto T, Kotwicki S, Aydin K, Williamson N (2010) Assessment of the walleye pollock stock in the eastern Bering Sea. In: 2010 North Pacific groundfish stock assessment and fishery evaluation reports for 2011. North Pacific Fishery Management Council, Anchorage, AK

Knoth BA, Foy RJ (2008) Temporal variability in the food habits of arrowtooth flounder Atheresthes stomias in the Western Gulf of Alaska. NOAA Tech Memo NMFSAFSC-184. US Department of Commerce, Seattle, WA

Kotwicki S, Buckley TW, Honkalehto T, Walters G (2005) Variation in the distribution of walleye pollock (Theragra chalcogramma) with temperature and implications for seasonal migration. Fish Bull 103:574-587

Litzow MA, Ciannelli L (2007) Oscillating trophic control induces community reorganization in a marine ecosystem. Ecol Lett 10:1124-1134

Mueter FJ, Litzow MA (2008) Sea ice retreat alters the biogeography of the Bering Sea continental shelf. Ecol Appl 18:309-320

NPFMC (2010a) Fishery management plan for groundfish of the Bering Sea and Aleutian Islands management area. North Pacific Fishery Management Council, Anchorage, AK

NPFMC (2010b) North Pacific groundfish stock assessment and fishery evaluation reports for 2011. North Pacific Fishery Management Council, Anchorage, AK

Overland JE, Stabeno PJ (2004) Is the climate of the Bering Sea warming and affecting the ecosystem? EOS Trans Am Geophys Union 85:309-312

R Development Core Team (2009) R: a language and environment for statistical computing. R Foundation for Statistical Computing, Vienna

Schumacher J, Stabeno PJ (1998) The continental shelf of the Bering Sea. In: Robinson AR, Brink KH (eds) The sea, the global coastal ocean: regional studies, synthesis, Book XI. Wiley, New York, NY, p 789-822

Spencer PD (2008) Density-independent and densitydependent factors affecting temporal changes in spatial distributions of eastern Bering Sea flatfish. Fish Oceanogr 17:396-410

Stabeno PJ, Hunt GL Jr (2002) Overview of the inner front and southeast Bering Sea carrying capacity programs. Deep-Sea Res II 49:6157-6168

Editorial responsibility: Nicholas Tolimieri, Seattle, Washington, USA
Stabeno PJ, Bond NA, Kachel NB, Salo SA, Schumacher JD (2001) On the temporal variability of the physical environment over the south-eastern Bering Sea. Fish Oceanogr 10:81-98

Stabeno PJ, Bond NA, Salo SA (2007) On the recent warming of the southeastern Bering Sea shelf. Deep-Sea Res II 54:2599-2618

Stahl JP, Kruse GH (2008) Spatial and temporal variability in size at maturity of walleye pollock in the Eastern Bering Sea. Trans Am Fish Soc 137:1543-1557

Stark JW (2008) Age- and length-at-maturity of female arrowtooth flounder (Atheresthes stomias) in the Gulf of Alaska. Fish Bull 106:328-333

Swain DP, Benoit HP (2006) Change in habitat associations and geographic distribution of thorny skate (Amblyraja radiata) in the southern Gulf of St Lawrence: densitydependent habitat selection or response to environmental change? Fish Oceanogr 15:166-182

Swain DP, Wade EJ (1993) Density-dependent geographic distribution of Atlantic cod (Gadus morhua) in the southern Gulf of St Lawrence. Can J Fish Aquat Sci 50:725-733

> Thrush SF, Pridmore RD, Hewitt JE (1994) Impacts on soft sediment macrofauna - the effects of spatial variation on temporal trends. Ecol Appl 4:31-41

Turnock BJ, Wilderbuer TK (2009) Gulf of Alaska arrowtooth flounder stock assessment. In: 2009 North Pacific groundfish stock assessment and fishery evaluation reports for 2010. North Pacific Fishery Management Council, Anchorage, AK

> Walters C, Kitchell JF (2001) Cultivation/depensation effects on juvenile survival and recruitment: implications for the theory of fishing. Can J Fish Aquat Sci 58:39-50

> White JW, Caselle JE (2008) Scale-dependent changes in the importance of larval supply and habitat to abundance of a reef fish. Ecology 89:1323-1333

Wilderbuer TK, Hollowed AB, Ingraham WJ, Spencer PD, Conners ME, Bond NA, Walters GE (2002) Flatfish recruitment response to decadal climatic variability and ocean conditions in the eastern Bering Sea. Prog Oceanogr 55:235-247

Wilderbuer TK, Nichol DG, Aydin KY (2009) Arrowtooth flounder. In: 2009 North Pacific groundfish stock assessment and fishery evaluation reports for 2010. North Pacific Fishery Management Council, Anchorage, AK

Witherall D, Pautzke C (1997) A brief history of bycatch management measures for eastern Bering Sea groundfish fisheries. Mar Fish Rev 59:15-22

Wyllie-Echeverria T, Wooster WS (1998) Year-to-year variations in Bering Sea ice cover and some consequences for fish distributions. Fish Oceanogr 7:159-170

Yang MS, Nelson MW (2000) Food habits of the commercially important groundfishes in the Gulf of Alaska in 1990, 1993, and 1996. NOAA Tech Memo NMFS-AFSC112. US Department of Commerce, Seattle, WA

Submitted: January 21, 2011; Accepted: July 22, 2011

Proofs received from author(s): September 23, 2011 